\title{
O IMPACTO DA JUDICIALIZAÇÃO DA SAÚDE NA COMARCA DE PELOTAS
}

Impact of healthcare legal enforcement in Pelotas District

${ }^{1}$ Universidade Federal de Pelotas. Pelotas/RS, Brasil.

Correspondência: Guilherme Camargo Massaú. E-mail: uassam@gmail.com.

Recebido em: 05/11/2013. Aprovado em: 10/04/2014. 


\section{RESUMO}

O objetivo do texto é desvelar o impacto da judicialização da saúde na Comarca de Pelotas. A Constituição Federal de 1988 consolidou o direito e o acesso à saúde. Assim, a saúde passou a fazer parte dos planos de políticas públicas do Estado, tendo este a obrigação de garantir o direito à saúde por meio de seu acesso. Contudo, por questões administrativas e financeiras, o Estado-administrador tem dificuldades de ofertar a todos os indivíduos o acesso à saúde. Por conseguinte, o Judiciário passa a ser a via de concretização desse acesso para aqueles que não o obtiveram via administração. Destarte, tentou-se mostrar a procura do Judiciário na Comarca de Pelotas, especificamente na $6^{\text {a }}$ Vara Cível da Justiça Estadual, e o impacto nas finanças do Município de Pelotas dela decorrente.

\section{Palavras-chave}

Direito à saúde; Judicialização; Município de Pelotas; República.

\section{ABSTRACT}

This study aims to reveal healthcare legal enforcement impact in Pelota District. The 1988 Federal Constitution combined the right to health via access to healthcare. Thus, healthcare became a part of the government's public policy plans. The government bore the responsibility of assuring the right to health by public healthcare access. However, due to administrative and financial issues, the administrative government faces some difficulty in offering healthcare access to all individuals. Therefore, the judiciary has become the means to implement this access for those who have not obtained it via the administration. Thus, this study attempted to demonstrate the demand in Pelota judiciary district, especially the 6th Civil Court of State Justice, and to show the resulting impact on the economy of the municipality of Pelotas.

\section{Keywords}

Right to Healthcare; Legal Enforcement; Municipality of Pelotas; Republic. 


\section{Introdução}

A complexa estrutura para o oferecimento de garantias ao direito à saúde requer do Estado um aporte financeiro considerável, ou seja, as despesas que envolvem os serviços de saúde são de elevada monta devido à própria natureza dos serviços. Não se trata, apenas, de consultas isoladas ou atendimentos de emergência, mas também do fornecimento continuado de remédios, do tratamento prolongado de doenças e da internação do paciente por tempo considerável, além de outros serviços que exigem investimentos onerosos por parte do promovedor de tais serviços. Ainda, é preciso levar em consideração que o acesso a tais serviços deve ser universal e igualitário a todos os indivíduos que deles necessitarem, fato que exige um dispêndio considerável do Estado.

De fato, o Estado mantém uma estrutura significativamente complexa para cumprir com seu dever constitucional de oferecer o acesso à saúde a todos os indivíduos. Porém, nem sempre a administração estatal consegue abranger todos aqueles que precisam dele. A consequência disso é que a prestação - que inicialmente deveria se dar apenas pelo âmbito administrativo - é judicializada: recorre-se ao Judiciário para se conseguir o devido acesso ao serviço de saúde. Por sua vez, o Judiciário, ao reconhecer o direito do pleiteante, muitas vezes em tutela de urgência (visto que, em se tratando de saúde, a necessidade de urgência encontra-se implícita), ordena que o Estado realize o devido serviço e garanta o direito fundamental.

O Judiciário constitui-se como uma via de acesso à saúde que impacta na administração, pois os gastos oriundos das demandas judiciais não se encontram previstos no orçamento. Trata-se de um adendo de volumosa quantia nas despesas que não foram previstas. Isso fica mais crítico quando o ente federativo do qual se exige o cumprimento da decisão judicial é o município. Tal ente possui, geralmente, um orçamento mais enxuto do que o do estado e o da União. Este artigo busca trazer alguns números referentes aos gastos ordinários do Município de Pelotas, por meio da Secretaria Municipal de Saúde, e das demandas judiciais oriundas da $6^{a}$ Vara Cível da Comarca de Pelotas.

Os dados apresentados tornam possível a formação de uma ideia, mesmo que relativa, do tamanho da problemática enfrentada pelo Estado-administração e pelo Estado-jurisdição em relação ao acesso ao serviço de saúde no âmbito municipal.

\section{0 conceito de saúde e a natureza do direito à saúde}

A saúde, a partir da conceituação dada pela Organização Mundial da Saúde (OMS), é definida como "um completo estado de bem-estar físico, mental e social e 
não apenas ausência de doença ou enfermidade"'. Devido ao alto grau de abstração que tal conceito requer para sua interpretação, inúmeras críticas têm sido aventadas, seja pela utópica ideia de "completo", seja pela imprecisa ideia de "bem-estar"2. Não obstante a pertinência de tais críticas, o fato que ora nos importa é o do caráter ampliativo do conceito, delimitando-o para além da "ausência de doença". Isso porque tal ampliação ajuda-nos a entender a natureza jurídica do direito à saúde.

Com efeito, o direito à saúde foi constitucionalmente elencado no rol dos direitos sociais, os quais, por sua vez, são historicamente classificados como direitos fundamentais de segunda geração. Dizem respeito principalmente (mas não somente $^{3}$ ) àqueles que exigem uma prestação positiva estatal, por meio da implantação de políticas públicas ${ }^{4}$ para sua concretização, fugindo à regra dos chamados direitos de primeira geração, que consagraram a prestação negativa do Estado como forma de garantia das liberdades individuais.

A Carta Política é clara ao defini-lo como direito fundamental. Isso implica - ou pelo menos assim o deveria fazer - uma proteção constitucional mais intensa, gerando, conforme aduzido por Geisa de Assis Rodrigues em obra específica sobre o tema ${ }^{5}$, um compromisso jurídico de sua concretização vinculado às funções do Estado Social. Nesse sentido:

Segundo o artigo 196 da Constituição Federal, a saúde é o direito à redução do risco de doença e de outros agravos, mediante o acesso às ações e serviços de promoção, proteção e recuperação. Com efeito, o objeto do direito à saúde abriga elementos que ensejam a perpetuação da própria condição vital. Além disso, o direito à saúde é passaporte para a potencialização dos atributos da vida, permitindo que a mesma se realize em toda a sua plenitude. De conseguinte, o direito à saúde tem uma configuração de direito fundamental em nosso sistema jurídico, posto que o direito à vida

\footnotetext{
${ }^{1}$ Preâmbulo da Constituição da OMS, adotada em 22 de julho de 1946, durante a Conferência Internacional de Saúde realizada em Nova lorque. CONSTITUTION OF THE WORLD HEALTH ORGANIZATION. Disponível em: <http://apps.who.int/gb/bd/PDF/bd47/EN/constitution-en.pdf>. (tradução livre) e CONSTITUIÇÃO DA ORGANIZAÇÃO MUNDIAL DA SAÚDE (OMS/WHO) - 1946. Disponível em: <http://www.direitoshumanos.usp. br/index.php/OMS-Organiza\%C3\%A7\%C3\%A3o-Mundial-da-Sa\%C3\%BAde/constituicao-da-organizacao-mundial-da-saude-omswho.html>. Acesso em: 03 jul. 2013.

${ }^{2}$ LUNARDI, Valéria Lerch. Problematizando conceito de saúde, a partir do tema da governabilidade dos sujeitos. Revista Gaúcha de Enfermagem, Porto Alegre, v. 20, n. 1, p. 26-40, jan. 1999. Disponível em: <http:// seer.ufrgs.br/RevistaGauchadeEnfermagem/article/view/4219/2229>. Acesso em: 15 jun. 2013.

${ }^{3}$ Nesse sentido, mencionando os "direitos dos trabalhadores" como exceção à regra prestacional: SARLET, Ingo Wolfgang. Os direitos fundamentais sociais na constituição de 1988. Revista Diálogo Jurídico, Salvador, ano 1, v. 1, n. 1, p. 18, abr. 2001. Disponível em: <http://direitopublico.com.br/revistas/17082706/ revista-dialogo-juridico-01-2001-ingo-sarlet.pdf>. Acesso em: 18 abr. 2013.

${ }^{4}$ KÖLLING, Gabrielle; MASSAÚ, Guilherme Camargo. A concretização do direito à saúde na perspectiva republicana. Revista de Direito Sanitário, São Paulo, v. 12, n. 2, p. 11-36, 2011. Disponível em: <http://www. revistas.usp.br/rdisan/article/view/13247/15064>. Acesso em: 03 set. 2013.

${ }^{5}$ RODRIGUES, Geisa de Assis. Direito sanitário. In: NUNES JÚNIOR, Vidal Serrano (Org.). Manual de direitos difusos. São Paulo, Verbatim, 2009. p. 293.
} 
é inegavelmente um direito fundamental, consoante o caput do artigo $5^{\circ}$ de nossa Constituição. Na verdade, o exercício pleno da dignidade da pessoa humana pressupõe a prevenção de doenças e agravos à saúde e a promoção de ações de tratamento do bem-estar físico e mental debilitado. Assim, nem mesmo aqueles partidários das concepções mais restritivas de classificação de direitos fundamentais podem deixar de reconhecer no direito à saúde a sua essência fundamental (...) é garantido mediante políticas sociais e econômicas que visem à redução do risco de doença e de outros agravos e ao acesso universal e igualitário às ações e serviços para sua promoção, proteção e recuperação. Destarte, no atual sistema brasileiro de atendimento universal todos são titulares do direito à saúde ${ }^{6}$.

A partir do reconhecimento da saúde como direito fundamental garantido constitucionalmente a todas as pessoas, resta como conclusão lógica que todos são credores, e o Estado - ou quem o represente na função administrativa - é o devedor da obrigação. Isso se traduz na possibilidade e no reconhecimento da exigibilidade do efetivo cumprimento da obrigação legalmente estabelecida. Ademais, conforme advertem Gilmar Mendes e Paulo Gustavo Gonet Branco, dizer que a norma do Artigo 196 da Constituição Federal de $1988\left(\mathrm{CF} / 88^{7}\right)$, por tratar de um direito social, consubstancia-se tão somente em norma programática, incapaz de produzir efeitos, apenas indicando diretrizes a serem observadas pelo poder público, significaria negar a força normativa da Constituição ${ }^{8}$.

Formula-se, destarte, a clássica concepção de relação jurídica, figurando: qualquer pessoa no polo ativo (credor); o Estado lato sensu no polo passivo (devedor); e um rol não taxativo - em razão da amplitude do indigitado conceito de saúde, como visto - de medidas preventivas (profiláticas) e combativas (terapêuticas) como objeto prestacional (saneamento básico, vigilância sanitária, educação e conscientização sanitária, fornecimento de medicamentos e procedimentos cirúrgicos etc.).

\section{O Sistema Único de Saúde e sua efetividade}

Ao comando esculpido no texto constitucional não importa a maneira pela qual dita prestação - que concerne à discricionariedade do poder estatal - será satisfeita, seja pela implementação de políticas públicas eficazes, seja pelo fomento e incentivo à iniciativa privada e ao terceiro setor, ou ainda por comandos judiciais consubstanciados em uma obrigação de fazer (fornecimento de medicamentos etc.).

${ }^{6}$ RODRIGUES, Geisa de Assis. op. cit., p. 294-296.

${ }^{7}$ BRASIL. Constituição da República Federativa do Brasil de 1988. Disponível em: <http://www.planalto.gov. br/ccivil_03/constituicao/constituicaocompilado.htm>. Acesso em: 03 set. 2014.

${ }^{8}$ MENDES, Gilmar Ferreira; BRANCO, Paulo Gustavo Gonet. Curso de direito constitucional. São Paulo: Saraiva, 2011. p. 686. 
Dito isso, todavia, não se pode negar que, na configuração atual do Estado brasileiro, desde a superação da ideia pura do liberalismo, a forma prestacional calcada na implantação de políticas públicas pelo poder público é a que tem maior legitimidade constitucional e social.

Trata-se de norma constitucional imperativa aquela expressada nos artigos 196 e seguintes da CF/88, que, dentre outras inovações, instituiu o Sistema Único de Saúde (SUS) como método integrador de forças públicas das esferas federal, estadual e municipal. Ou ainda, nos exatos termos da Constituição, uma rede "regionalizada" e "hierarquizada" (Artigo 198, caput).

Explanando sobre ditos conceitos, vale a lição de Guido Carvalho e Lenir Santos ${ }^{9}$ :

\begin{abstract}
A hierarquização supõe três ou quatro níveis de complexidade da atenção integral à saúde, incluindo a assistência médica e hospitalar, organizados cada qual com resolutividade própria. A regionalização - como distribuição especial de serviços de saúde, de qualquer nível de complexidade, organizados para atender à população de uma região - exige simultânea hierarquização desses níveis, cada qual com resolutividade própria. Conhecer primeiro as necessidades e os serviços e, no processo social, hierarquizá-los e regionalizá-los.
\end{abstract}

A grande controvérsia prática surge no que tange à questão do investimento público e da concretização da política de saúde para o consequente financiamento adequado do SUS. Aliás, cabe a crítica de ser essa a práxis observada em um Estado que intenciona estender sua mão de controle sobre todas as áreas da sociedade - muitas vezes como artifício de manobra política -, independentemente de condições de alocação de recursos ou de necessidade, prejudicando as áreas imprescindíveis à garantia da vida, como aquela em comento. Trata-se da velha máxima: recursos escassos, necessidades infinitas.

Após 12 anos (a partir do marco da Emenda Constitucional n. $29^{10}$ ) e um longo período de discussões no Congresso Nacional, com o advento da Lei Complementar n. 141/2012 ${ }^{11}$, houve a tão esperada regulamentação da matéria no âmbito

\footnotetext{
${ }^{9}$ Apud. RODRIGUES, Geisa de Assis. op. cit., p. 325.

${ }^{10}$ BRASIL. Presidência da República. Emenda Constitucional n. 29, de 13 de setembro de 2000. Altera os arts. 34, 35, 156, 160, 167 e 198 da Constituição Federal e acrescenta artigo ao Ato das Disposições Constitucionais Transitórias, para assegurar os recursos mínimos para o financiamento das ações e serviços públicos de saúde. Disponível em: <http://www.planalto.gov.br/ccivil_03/constituicao/Emendas/Emc/ emc29.htm>. Acesso em 03 set. 2014.

${ }^{11}$ BRASIL. Presidência da República. Lei Complementar n. 142, de 13 de janeiro de 2012. Regulamenta o § 3o do art. 198 da Constituição Federal para dispor sobre os valores mínimos a serem aplicados anualmente pela União, Estados, Distrito Federal e Municípios em ações e serviços públicos de saúde; estabelece os critérios de rateio dos recursos de transferências para a saúde e as normas de fiscalização, avaliação e controle das despesas com saúde nas 3 (três) esferas de governo; revoga dispositivos das Leis ns. 8.080, de 19 de setembro de 1990, e 8.689, de 27 de julho de 1993; e dá outras providências. Disponível em: <http://www.planalto.gov.br/ccivil_03/leis/LCP/Lcp141.htm>. Acesso em: 03 set.2014.
} 
infraconstitucional, conforme comando do parágrafo $3^{\circ}$, Artigo 198 da CF/88. Tal regulamentação visa, principalmente, à definição de ações e serviços de saúde e à correção de distorções na vinculação de recursos da União ${ }^{12}$.

Vale destacar, portanto, a forma como o legislador determinou a questão do financiamento do SUS.

O Artigo $5^{\circ}$ da LC n ${ }^{\circ} 141 / 2012$, no seu caput, chama a atenção para a aplicação nas ações e nos serviços públicos de saúde do valor correspondente ao montante empenhado no exercício financeiro anterior, ao qual ainda será acrescido de, no mínimo, o percentual correspondente à variação nominal do Produto Interno Bruto (PIB), cujo marco temporal é o ano anterior ao da lei orçamentária anual. O parágrafo $2^{\circ}$ do citado artigo prevê o caso de variação no PIB; se esta tiver índice negativo, o valor de que trata o caput não poderá ser reduzido (em termos nominais) de um exercício financeiro para o outro.

Já o Artigo $6^{\circ}$ da LC n. 141/2012 estabelece que os estados e o Distrito Federal aplicarão, anualmente, o mínimo de $12 \%$ da arrecadação dos impostos previstos no Artigo 155 da CF/88 e dos recursos referentes ao Artigo 157 da CF/88, e a alínea "a" do inciso I e o inciso II do caput do Artigo 159 da CF/88, sendo deduzidas as parcelas transferidas aos municípios.

Da mesma maneira, o Artigo $7^{\circ}$ da referida lei complementar regula a aplicação dos recursos em saúde pelos municípios e Distrito Federal. Ambos aplicarão anualmente $15 \%$ da arrecadação dos impostos referentes ao Artigo 156 da $\mathrm{CF} / 88$, dos recursos retirados do Artigo 158 da CF/88 e da alínea "b" do inciso I do caput e do parágrafo $3^{\circ}$ do Artigo 159 da CF/88.

Por fim, o Artigo $8^{\circ}$ trata do Distrito Federal, que deverá aplicar anualmente $12 \%$ do produto da arrecadação direta dos impostos que não possam ser segregados em base estadual e municipal.

A LC n. 141/2012 prevê, ainda, em seu Artigo $9^{\circ}$, que a base de cálculo dos percentuais dos estados, do Distrito Federal e dos municípios abarca qualquer compensação financeira oriunda de impostos e transferências constitucionais previstos no parágrafo $2^{\circ}$ do Artigo 198 da $\mathrm{CF} / 88$, tanto os instituídos quanto os que vierem a ser criados, além da dívida ativa, de multa e dos juros de mora decorrentes dos impostos cobrados diretamente ou por meio de processos administrativos ou judiciais. O Artigo $10^{\circ}$ estabelece o montante para o cálculo de recursos previstos no parágrafo $3^{\circ}$ do Artigo $5^{\circ}$ e nos artigos $6^{\circ}$ e $7^{\circ}$, devendo ser levados em conta os recursos decorrentes da dívida ativa, de multa e dos juros de mora oriundos dos impostos e da respectiva dívida ativa. No Artigo 11 está previsto que os estados, o Distrito Federal e os municípios deverão observar as respectivas constituições ou leis

\footnotetext{
${ }^{12}$ MENDES, Gilmar Ferreira; BRANCO, Paulo Gustavo Gonet. op. cit., p. 691.
} 
orgânicas em caso de seus percentuais serem superiores aos fixado na LC n. 141/2012, a fim de aplicá-los em ações e serviços públicos de saúde.

O comando constitucional era enfático no sentido da necessidade de regulamentação infraconstitucional, o que ocorreu de forma demasiadamente tardia, em uma clara demonstração de omissão legislativa - deixando de atuar efetivamente em algumas das áreas mais importantes e ferindo qualquer ideia de representatividade que dito poder deveria ter por primazia. Todavia, é possível constatar o esforço da legislação complementar em destinar recursos para aplicação em ações e serviços públicos, principalmente aqueles oriundos de multas, da dívida ativa e dos juros de mora dos impostos.

Não cabe adentrar no mérito da proposta legislativa e nos motivos pelos quais a mesma apresentou-se entravada ${ }^{13}$. O fato inegável é que sua regulamentação deve, ao menos em um período de médio/longo prazo, trazer benefícios diversos. O primeiro deles diz respeito à segurança jurídica alcançada pela delimitação da abrangência de "ações e serviços públicos de saúde" (embora ainda excessivamente amplo, ex vi artigos $2^{\circ}$ e $3^{\circ}$, LC n. 141/2012), haja vista a máquina pública trabalhar sempre limitada pela chamada reserva do possível, fazendo com que assim sejam direcionados valores somente àquelas áreas que se enquadrem nesse conceito de relevância pública.

O outro, igualmente importante, diz respeito à possibilidade de, em se definindo os critérios mínimos de investimento e repasse, tornar-se possível um controle mais eficaz da atividade do gestor público, seja sob a ótica da responsabilização administrava, seja sob a ótica da responsabilização fiscal.

Os resultados concretos, todavia, ainda se apresentam distantes, como se pode abstrair das notícias diariamente veiculadas pela mídia e das incontáveis ações judiciais que são propostas. Mesmo com a referida regulamentação, muito provavelmente ainda não ocorre o adequado aproveitamento dos recursos disponíveis ou a LC n. 141/2012 não estabeleceu recursos suficientes, restando inegável que o SUS apresenta-se como uma política pública com falhas graves quanto a sua aplicação, sua manutenção e suas perspectivas.

Em um panorama geral do SUS nos diversos municípios brasileiros, a situação costumeiramente se repete: falta de repasses de um ente federativo para o outro; falta de profissionais da saúde interessados em razão de um plano de carreira

\footnotetext{
${ }^{13} T a l$ questão convergiu com a criação de um novo tributo em substituição à CPMF e com a proposta da retirada do percentual mínimo de aplicação em saúde a dedução da receita oriunda do FUNDEB - conflito entre direitos de maior relevância: saúde x educação -, dentre outras controvérsias políticas e financeiras. CNS defende a regulamentação da EC n. 29. Conselho Nacional de Saúde. Disponível em: <http://conselho.saude.gov.br/webec29/index.html.> Acesso em: 26 ago. 2013 e FUNDEB pode financiar saúde. Carta Capital. Disponível em: <http://www.cartacapital.com.br/politica/fundeb-pode-financiar-saude>. Acesso em 26 ago. 2013. Acesso em: 26 ago. 2013.
} 
pouco atrativo; falta de leitos; filas nos corredores de hospitais; centralização no atendimento (prontos-socorros) devido à ausência de unidades básicas; má gestão; falta de medicamentos nas farmácias populares; dentre outros fatores.

No estudo e análise das políticas governamentais - como aquela ora em comento, o SUS -, conforme asseverado por Lasswell, deve-se responder às seguintes perguntas em relação à ação estatal: quem ganha o quê, por quê e que diferença ela faz ${ }^{14}$. Em geral, quando da proposição, formulação e aplicação das políticas públicas, faz-se necessária a compreensão de diversos aspectos, como a "autonomia relativa do Estado"15 - viabilizadora da governabilidade - cotejada com influências externas e internas - vários atores e níveis de decisão, grupos de pressão etc.--, sempre tendo em vista que:

Essa autonomia relativa gera determinadas capacidades, as quais, por sua vez, criam as condições para a implementação de objetivos de políticas públicas. A margem dessa "autonomia" e o desenvolvimento dessas "capacidades" dependem, obviamente, de muitos fatores e dos diferentes momentos históricos de cada país ${ }^{16}$.

Em meio à classificação adotada por Theodor Lowi (distributivas, regulatórias, redistributivas e constitutivas), pode-se incluir o rol das políticas públicas de saúde no formato das políticas públicas redistributivas, “(...) que atinge maior número de pessoas e impõe perdas concretas e no curto prazo para certos grupos sociais, e ganhos incertos e futuros para outros; são, em geral, as políticas sociais universais (...) $)^{17}$, tratando-se, ademais, daquelas de maior dificuldade de encaminhamento.

Inegável que a problemática da saúde é, senão a maior, uma das maiores preocupações da população, e que qualquer discurso eleitoral que apresente indícios da possibilidade de ser solucionado o problema ganha a força de um espantoso apoio popular. Ora, cumpre fazer a reflexão: se há praticamente um consenso acerca da importância das ações públicas para a solução do problema - discordando desse ponto de vista apenas os defensores de um Estado mínimo -; se os agentes políticos (e demais atores de decisão) sabem disso - e com isso muitas vezes se beneficiam -; se é notório o fato de que, embora tenham impactos no curto prazo, trata-se de ações de longo prazo - e por isso devem ser planejadas com cuidado, mas exercidas progressivamente a fim de não se estagnarem -; se há comando constitucional

\footnotetext{
${ }^{14}$ SOUZA, Celina. Políticas públicas: uma revisão da literatura. Revista Sociologias, Porto Alegre, ano $8, \mathrm{n}$. 16, p. 20-25, jul./dez. 2006. SciELO Brasil. Disponível em: <http://www.scielo.br/pdf/soc/n16/a03n16>. Acesso em: 03 set. 2013.

15“Pode-se, então, resumir política pública como o campo do conhecimento que busca, ao mesmo tempo, 'colocar o governo em ação' e/ou analisar essa ação (variável independente) e, quando necessário, propor mudanças no rumo ou curso dessas ações (variável dependente). A formulação de políticas públicas constitui-se no estágio em que os governos democráticos traduzem seus propósitos e plataformas eleitorais em programas e ações que produzirão resultados ou mudanças no mundo real”. Id. Ibid., p. 26.

${ }^{16}$ dd. Ibid., p. 27.

${ }^{17}$ Id. Ibid., p. 28
} 
imperativo no sentido de ser a saúde garantida a todos; se há avanços na ciência médica, tanto na descoberta de doenças quanto na prevenção e tratamento... Por que uma solução continua aparentemente tão distante?

Diante de todas essas questões de direito, conjuntamente com a ineficiência do Estado-administração em oferecer o acesso à saúde, existe uma demanda ao Judiciário para que seja garantido o acesso à saúde, já que os gestores públicos não conseguem atender toda a demanda derivada dos direitos e das garantias da Constituição de 1988. As políticas públicas buscam atender essa demanda. Porém, enquanto não conseguem satisfazê-la, o Judiciário assume, por meio das ações judiciais, uma função de garantidor e gestor do acesso à saúde ${ }^{18}$.

\section{A judicialização da saúde}

Da falta de efetividade, decorrente de vários fatores administrativos, políticos e econômicos, advém a judicialização excessiva do direito à saúde ${ }^{19}$.

Como dito, se há o reconhecimento da saúde como direito fundamental subjetivo, há de ser reconhecida, como regra, a sua imediata exigibilidade. Nesse sentido:

É certo que, se não cabe ao Poder Judiciário formular políticas sociais e econômicas na área da saúde, é sua obrigação verificar se as políticas eleitas pelos órgãos competentes atendem aos ditames constitucionais do acesso universal e igualitário. Pode ocorrer de medicamentos requeridos constarem das listas do Ministério da Saúde, ou de políticas públicas Estaduais ou Municipais, mas não estarem sendo fornecidos à população por problemas de gestão: há política pública determinando o fornecimento do medicamento requerido, mas, por problemas administrativos do órgão competente, o acesso está interrompido. Nesses casos, o cidadão individualmente considerado não pode ser punido pela ação administrativa ineficaz ou pela omissão do gestor do sistema de saúde em adquirir os fármacos considerados essenciais, em quantidades suficientes para atender à demanda. Não há dúvida de que está configurado um direito subjetivo à prestação de saúde, passível de efetivação por meio do Poder Judiciário ${ }^{20}$.

\footnotetext{
${ }^{18}$ MARQUES, Silvia Badim. Judicialização do direito à saúde. Revista de Direito Sanitário, São Paulo, v. 9, n. 2, p. 65-72, 2008. Disponível em: <http://www.revistas.usp.br/rdisan/article/view/13117/14920>. Acesso em: 15 jun. 2013.

${ }^{19}$ BARROSO, Luís Roberto. Da falta de efetividade à judicialização excessiva: direito à saúde, fornecimento gratuito de medicamentos e parâmetros para a atuação judicial. Rio de Janeiro, 2007. p. 3-4. Disponível em: <http://download.rj.gov.br/documentos/10112/168750/DLFE-29287.pdf/rev630402Dr.LuisRobertoBarroso.pdf>. Acesso em: 05 set. 2013.

${ }^{20}$ MENDES, Gilmar Ferreira; BRANCO, Paulo Gustavo Gonet. op. cit., p. 706-707.
} 
O posicionamento do Supremo Tribunal Federal acerca da possibilidade e dos limites da atuação judiciária vem sendo formado com as várias decisões proferidas ao longo do tempo e tem ainda, como marco definidor, a audiência pública lá realizada no ano de 2009, motivada pela "existência de um número significativo de demandas judiciais relacionadas ao direito à saúde", tendo "a finalidade especial de promover a participação social por meio de depoimentos de pessoas com experiência e autoridade no que concerne ao Sistema Único de Saúde, em suas várias vertentes". A conclusão se deu no sentido de que "os casos de omissão e de falhas de implementação do sistema como um todo não podem ser resolvidos com uma ação isolada de um único ente, eventualmente o próprio Judiciário" e de que "deve ser reforçada, por sua vez, a ação conjunta dos entes federativos no cumprimento do mandamento constitucional" 21 .

Ou seja, concluiu-se que é possível o controle jurisdicional sem ferir a separação de poderes, desde que sejam respeitados limites para a atuação $0^{22}$ e que não sejam consideradas como únicas soluções aquelas tomadas individualmente no caso concreto.

Importa agora dizer que, não obstante os avanços - direcionamento do entendimento jurisprudencial da Suprema Corte; a consciência acerca da necessidade de serem realizados em conjunto entre os entes federados o planejamento e a tomada de ações; a importância dos Conselhos de Saúde como forma de efetiva participação popular etc. -, a realidade dos tribunais não é outra senão a de superlotação de processos.

\section{0 caso do município de Pelotas}

Consoante o anteriormente asseverado, o objeto do presente trabalho consiste na análise crítica e contextual dos dados coletados junto à 6a Vara Cível da Comarca de Pelotas e das informações fornecidas pela Secretaria Municipal de Saúde de Pelotas ${ }^{23}$. Tais elementos não proporcionam a exatidão da relação entre as demandas judiciais e o valor gasto pelo município com tais demandas, mas oferece uma estimativa da demanda e da verba decorrente desta no município de Pelotas.

\footnotetext{
${ }^{21}$ MENDES, Gilmar Ferreira; BRANCO, Paulo Gustavo Gonet. op. cit., p. 713-714.

${ }^{22}$ Barroso (2007) conceitua tais limites como "Parâmetros para racionalizar e uniformizar a atuação judicial no fornecimento de medicamentos", citando, entre outros, que "o Judiciário só pode determinar a inclusão, em lista, de medicamentos de eficácia comprovada, excluindo-se os experimentais e os alternativos”. BARROSO, Luís Roberto. op. cit., p. 32.

${ }^{23}$ Pelotas está localizada na região Sul do Estado do Rio Grande do Sul, à beira da Lagoa dos Patos, distante 250 km da Capital, Porto Alegre. Segundo o Instituto Brasileiro de Geografia e Estatística (IBGE), em 2010, o município de Pelotas contava com uma população de 328.275 e a estimada em 2012 é de 329.435. A densidade demográfica é de 203,89 (hab/ km²) em 2010. Em 2012, o IBGE levantou um total de 1245 óbitos (666 homens e 579 mulheres) no índice denominado de morbidades hospitalares. Em 2009, Pelotas contava com o total 165 estabelecimentos de saúde: 63 públicos e 102 privados. INSTITUTO BRASILEIRO DE GEOGRAFIA E ESTATÍSTICA. Disponível em: <http://www.ibge.gov.br>. Acesso em: 10 jun. 2013.
} 


\section{Administração: secretaria municipal de saúde}

A Lei Municipal n. 5.875/12 24 , que estima a receita e fixa a despesa do Município de Pelotas para o exercício de 2012, no seu Artigo $1^{\circ}$, caput, prevê a receita e fixa a despesa em R \$761.378.942,60. Para a saúde, estava prevista uma despesa de R\$169.020.516,85, sendo que a Secretaria Municipal de Saúde (administração direta) tinha previsto uma despesa de $\mathrm{R} \$ 163.081 .929,85$. A diferença de $\mathrm{R} \$$ 5.938.587,00 corresponde à verba repassada para órgãos da administração indireta. A Prefeitura Municipal de Pelotas (administração direta) apresenta as seguintes rubricas com as respectivas despesas: despesas correntes ( $\mathrm{R} \$ 151.571 .070,85)$; pessoal e encargos sociais ( $\mathrm{R} \$ 42.524 .323,85)$; contratação por tempo determinado ( $\mathrm{R}$ 5.607.918,00); salário-família ( $\mathrm{R} \$ 20.315,00)$; vencimentos e vantagens fixas - pessoa civil ( $\mathrm{R}$ \$ 23.119.322,00); obrigações patronais ( $\mathrm{R} \$ 3.057 .278,00)$; outras despesas variáveis - pessoal civil ( $\mathrm{R} \$ 2.815 .575,00)$; outras despesas de pessoal decorrentes de contratos de terceirização ( $\mathrm{R} \$ 2.200,00)$; auxílio-alimentação ( $\mathrm{R}$ \$ 2.761.452,00); obrigações patronais ( $\mathrm{R}$ \$ 5.140.263,85); outras despesas correntes ( $\mathrm{R} \$ 109.046 .747,00)$; diárias - pessoal civil $(\mathrm{R} \$ 568.960,00)$; material de consumo (R \$ 15.436.681,00); material, bem ou serviço para distribuição gratuita ( $\mathrm{R} \$$ 1.000,00); passagens e despesas com locomoção ( $\mathrm{R} \$ 671.800,00)$; serviços de consultoria ( $\mathrm{R} \$ 160.900,00)$; outros serviços de terceiros - pessoa física ( $\mathrm{R} \$ 2.630 .291,00)$; outros serviços de terceiros - pessoa jurídica $(\mathrm{R} \$ 83.273 .415,00)$; obrigações tributárias e contributivas ( $\mathrm{R}$ \$ 90.700,00); despesas de exercícios anteriores ( $\mathrm{R}$ \$ 6.205.900,00); indenizações e restituições (R $7.100,00)$; despesas de capital ( $\mathrm{R}$ \$ 11.510.859,00); investimentos ( $\mathrm{R}$ \$ 11.510.859,00); outros serviços de terceiros - pessoa jurídica ( $\mathrm{R} \$ 4.350 .160,00)$; obras e instalações ( $\mathrm{R}$ \$ 5.146.000,00); equipamento e material permanente ( $\mathrm{R}$ \$ 2.014.699,00). O total apresentado pelo relatório é de $\mathrm{R} \$ 163.081 .929,85^{25}$.

Os dados fornecidos pela Secretaria Municipal de Saúde trazem os seguintes valores gastos por ordem judicial (no ano de 2012): medicamentos (R 2.118.512,99); alimentação (R\$ 196.358,89); fraudas e insumos (R $206.140,05)$; exames e consultas $(\mathrm{R} \$ 15.980,00)$; tratamentos $(\mathrm{R} \$ 30.260,00)$; cirurgias $(\mathrm{R} \$ 132.687,51)^{26}$. Tais discriminações de gastos resultam em um total de $\mathrm{R} \$ 2.699 .939,44$. A média por mês, durante o ano, seria de R\$224.994,95; logo, em seis meses, resultaria em um gasto de $\mathrm{R} \$ 1.349 .969,72$. Por dia, seria o equivalente ao seguinte valor: $\mathrm{R} \$ 7.499,83$.

Essas perspectivas de gasto mostram, de forma relativa, o volume orçamentário que o município precisa despender para atender somente às decisões judiciais. Além disso, em meio a essas despesas “extraordinárias”, é preciso ter presente a ideia da continuidade das despesas orçamentárias relativas aos gastos ordinários com a

\footnotetext{
${ }^{24}$ PREFEITURA DE PELOTAS. Portal do Servidor. Disponível em: <http://externo.pelotas.com.br:51000>. Acesso em: 15 ago. 2013.

${ }^{25}$ Ressalta-se que se procurou reproduzir de forma simplificada o relatório, sendo o mais importante deixar consignados os gastos. Algumas rubricas repetem-se textualmente, mas os códigos são distintos, assim como os valores. PREFEITURA DE PELOTAS. Portal do Servidor, cit.

${ }^{26}$ Dados enviados por e-mail pela Secretaria Municipal de Saúde de Pelotas, no dia 13 de agosto de 2013.
} 
saúde, com a manutenção de postos de saúde, pronto-socorro e profissionais, com remédios distribuídos e com tratamentos, entre outros gastos com procedimentos de saúde. Assim, verifica-se a aguda problemática encarada pela administração municipal em relação ao orçamento disponível, à exigência da demanda judicial e aos demais gastos ordinários de saúde.

Pelo apresentado, o déficit orçamentário da Prefeitura Municipal de Pelotas é o equivalente aos valores das demandas judiciais, ou seja, a demanda orçamentária, no ano de 2012, excedeu $\mathrm{R} \$ 2.699 .939,44$ devido às decisões judiciais. Estima-se um total com saúde em 2012 de R\$171.720.456,29. Contudo, este valor representa menos de um quarto do orçamento total do município previsto em 2012, que foi de $\mathrm{R} \$ 761.378 .942,60$.

\section{Poder Judiciário: $6^{\text {a }}$ Vara Cível}

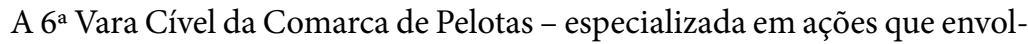
vam o interesse da fazenda pública (âmbitos municipal e estadual) - foi ativada no ano de 2008, após concentrada mobilização de advogados e procuradorias junto à presidência do Tribunal de Justiça do Estado do Rio Grande do Sul. Tal mobilização objetivava a reunião de todos os processos nos quais figurava como parte a Administração Pública (direta e indireta), facilitando o acesso aos autos e garantindo, também, uma prestação jurisdicional equânime.

Esta vara foi criada com a vultosa quantidade de quase dez mil ações já em trâmite, oriundas de outras varas cíveis e, pouco mais de cinco anos depois, seu quadro é composto por 23.320 ações em tramitação ${ }^{27}$.

Desse montante, a inegável maioria concerne às ações movidas por servidores públicos, visando ao pagamento de parcelas remuneratórias, indenizações e demais benefícios não pagos pela via administrativa. De outra banda, igualmente merecem destaque as ações constitucionais em tramitação (mandados de segurança, ações populares, ações civis públicas etc.), além das ações de execução fiscal, que visam à satisfação dos créditos fiscais, dentre outras.

Não obstante tal diversidade procedimental, o "ramo" que tem tido maior atenção - haja vista o caráter precípuo de urgência - é aquele composto pelas ações visando à proteção judicial do direito à saúde, seja para a realização de cirurgias ou exames, seja para o fornecimento de medicamentos. Tal fato constantemente torna-se pauta dos noticiários locais e tem dado um novo olhar à problemática da saúde em Pelotas.

\footnotetext{
${ }^{27}$ Informação obtida junto ao Juizado da 6a Vara Cível em 04 de setembro de 2013.
} 
Em um levantamento de dados feito no período compreendido entre os meses de julho e dezembro de 2012, foram contabilizados a quantidade mensal de ações com essa temática distribuídas na comarca, o tipo de representação (Figura 1) e o objeto propriamente dito de cada nova ação distribuída (Figura 2). Ainda, no final do levantamento de dados, o número total de processos versando sobre a temática do direito à saúde pode ser estimado $^{28} \mathrm{em} 1.604$ (correspondente a 6,7\% do total de processos em tramitação na Vara).

Quanto à Figura 1, embora o índice relativo à distribuição de novas ações mostre considerável variação entre os períodos (mínimo: 28 , máximo: 51 ), verifica-se a alta média de 40 novos processos por mês, o que equivale a aproximadamente 1,75 processo novo por dia.

No que tange ao tipo de representação, do total de 240 novas ações, não há surpresa em ser a Defensoria Pública a principal patrocinadora (130), haja vista o objeto de estudo estar intimamente ligado as suas funções institucionais de orientação jurídica e defesa dos necessitados. Giza-se o alto número de processos patrocinados por advogados particulares, no total de 91. Ainda, nesses seis meses, foram 19 ações propostas pelos serviços de assistência judiciária prestados pelas três faculdades de Direito da cidade ${ }^{29}$, que também são utilizados como ferramenta para a concretização do direito pela via judicial.

Em meio a tais informações, cabe ser ressaltado o número dessas ações que têm o Município de Pelotas como réu, seja de forma isolada, seja em litisconsórcio passivo com o Estado do Rio Grande do Sul: em julho de 2012, de 51 ações, o Município de Pelotas figurava como réu em 26; em agosto de 2012, foram 35 ações propostas, sendo 17 contra o Município; em setembro de 2012, foi um total de 33, das quais 17 tinham o Município como réu; em outubro de 2012, foram 50 ações, sendo 28 delas contra o Município; em novembro de 2012, foram 43 ações, sendo 20 contra a administração municipal; em dezembro de 2012, chegou-se ao número de 28 no total e 14 contra o Município. Logo, nesses seis meses de coleta de dados, foi proposto um total de 123 ações contra o Município de Pelotas, o que acarreta uma média mensal de 20,5 ações.

Quanto à Figura 2, cabe fazer ponderações a respeito de cada uma das "categorias" dos objetos.

Por primeiro, no que tange à categoria dos medicamentos, observou-se que não há um padrão quanto aos seus $\operatorname{custos}^{30}$ ou quanto à doença que acarretou

\footnotetext{
${ }^{28}$ Trata-se de estimativa em razão de a coleta ter sido feita junto ao próprio sistema informatizado por intermédio das classificações adotadas pelo Conselho Nacional de Justiça. Ocorre que, por se tratar de "novidade", possivelmente nem todos os processos mais antigos tinham sido inseridos na classificação, podendo, portanto, haver uma margem de variação a ser considerada.

${ }^{29}$ Universidade Federal Pelotas (UFPel), Universidade Católica de Pelotas (UCPel) e Anhanguera Educacional/Pelotas.

${ }^{30}$ llustra-se a discrepância com os valores obtidos em consulta junto ao site de buscas <www.buscapé.com. br>, em relação a alguns medicamentos pleiteados: Gabapentina $300 \mathrm{mg}$ com 30 cápsulas - $\mathrm{R} \$ 27,14$; Foraseq $12 / 400$ mcg com 60 cápsulas - $R \$ 54,17$; Seroquel Xro 300 mg com 30 comprimidos - $R \$ 617,70$ (em 22 de maio de 2013).
} 
Processos distribuídos e tipo de representação

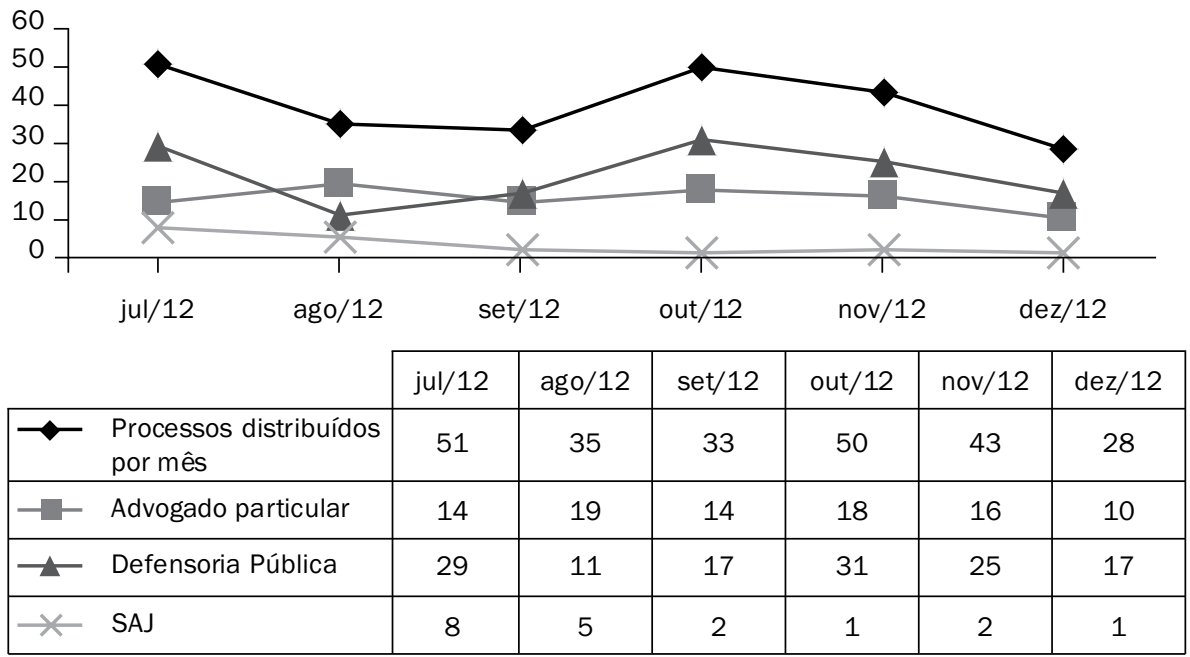

Figura 1. Tipo de representação.

Objeto das ações

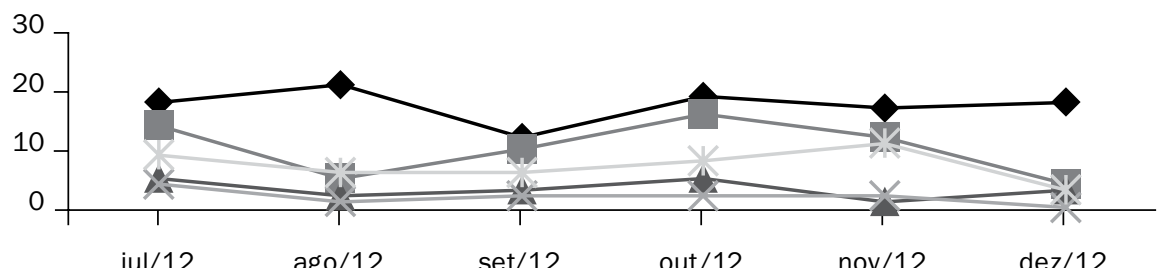

\begin{tabular}{|ll|c|c|c|c|c|}
\cline { 2 - 7 } \multicolumn{1}{c|}{} & jul/12 & ago/12 & set/12 & out/12 & nov/12 & dez/12 \\
\hline$\multimap$ & 18 & 21 & 12 & 19 & 17 & 18 \\
\hline$\longrightarrow$ Medicamentos & 14 & 5 & 10 & 16 & 12 & 4 \\
\hline$\leftarrow$ Cirurgia & 5 & 2 & 3 & 5 & 1 & 3 \\
\hline$\times \quad$ Internação & 4 & 1 & 2 & 2 & 2 & 0 \\
\hline$* \begin{array}{l}\text { Outros tratamentos } \\
\text { e/ou insumos }\end{array}$ & 9 & 6 & 6 & 8 & 11 & 3 \\
\hline
\end{tabular}

Figura 2. Objeto das ações. 
a necessidade de uso ${ }^{31}$. O que seguramente se pode afirmar é que a imensa maioria trata-se de remédios constantes na lista do SUS, ou seja, que deveriam ser fornecidos gratuitamente nas farmácias públicas. Pode-se afirmar, ainda, que dentre todas as categorias, a dos medicamentos é a de maior procura e, em razão de normalmente dizer respeito a tratamentos contínuos, os processos tendem a se perpetuar.

Em segundo, no que tange à categoria das cirurgias, igualmente não é possível se observar um padrão nos pedidos, nos custos e nos motivos da necessidade de sua realização. Nesse sentido, verificaram-se pedidos de realização de cirurgia/ bloqueio de valores para: retirada de tumores, artroplastia, artroscopia, gastroplastia, troca de próteses, vitrectomia etc. Diferentemente da primeira categoria, a pretensão refere-se a uma obrigação de prestação única, o que, em regra, faz os processos concernentes terem uma duração mais curta daqueles.

Relativamente à categoria dos exames/consultas, o exame mais vezes postulado foi o de ressonância magnética (5), seguido por tomografia (4), cintilografia miocárdica (2), eletroneuromiografia (1), polissonografia (1), colonoscopia (1), ecografia (1) e urotomografia (1), somados a três pedidos de consulta médica.

Em quarto lugar, no que diz respeito aos pedidos de internação, observou-se que sete referiam-se à internação hospitalar - sendo que um dos processos foi declinado para o Juizado da Infância e Juventude, por dizer respeito a interesse de menor -, e quatro referiam-se à internação compulsória - todos declinados para uma das Varas de Família em razão da matéria.

Por fim, no que tange à última categoria - pedidos de outros tratamentos e/ou insumos -, cabe ressaltar que a mesma é composta a partir da exclusão, em razão do seu não enquadramento nas outras categorias. Dentre os pedidos mais frequentes, verificou-se que 16 diziam respeito ao fornecimento de fraldas descartáveis, havendo também pedidos referentes ao fornecimento de colchão e de almofadas de ar (2), cadeira de rodas (1), tratamento para usuário de drogas (1), inseminação artificial (1), dentre outros.

Tais dados foram coletados em um período em que, por iniciativa do próprio juízo, foram realizadas reuniões mensais entre os profissionais da área - membros do Judiciário e da Defensoria Pública, advogados e representantes da Secretaria Municipal de Saúde, da $3^{\text {a }}$ Coordenadoria Regional de Saúde e do Conselho Municipal de Saúde -, e até mesmo pessoas diretamente interessadas como partes nos processos, com o escopo de se tornarem possíveis a análise da atual situação da saúde no Município de Pelotas e a propositura de soluções para os problemas encontrados.

\footnotetext{
${ }^{31}$ Por exemplo: doenças pulmonares, antidepressivos, asma, diabetes, gastrite, câncer, arritmia cardíaca etc.
} 
O fato de terem ocorrido tais reuniões pode representar uma hipótese influenciadora tanto em relação à diminuição dos gastos despendidos ${ }^{32}$ quanto em relação ao número de processos propostos - que não apresentou grandes variações entre os meses do período de coleta.

Essa circunstância leva a efeito a ideia de ser necessária a efetiva participação popular (direta e indiretamente), seja visando ao controle do poder público, seja buscando a união de esforços de todos os envolvidos para um fim comum - e, além disso, buscando uma adequada conceituação do direito a saúde. Vai ao encontro, ademais, do asseverado por Sueli Gandolfi Dallari, ao aduzir que somente a própria comunidade pode encontrar o adequado equilíbrio que assegura a saúde:

A existência e a efetividade desse controle popular podem ser, inclusive, verificadas pelo Poder Judiciário em cada momento da implementação das políticas públicas: desde a elaboração da lei até a prestação do serviço. Tratando-se do direito à saúde é, portanto, não só compatível, mas absolutamente necessário que os operadores do Direito contemporâneo examinem se as pessoas participaram da operação de tornar mais preciso o conceito de saúde naquela determinada comunidade, a fim de que pudesse ser utilizado pelos gestores públicos, encarregados de promover, proteger e cuidar da saúde das pessoas (...) para que se possa garantir, até as últimas instâncias, o direito à saúde, é preciso que a expressão "direito à saúde" tenha o mesmo sentido para as pessoas em geral, para os parlamentares, os gestores públicos e para os operadores do direito, e esse sentido só pode ser encontrado pelas próprias pessoas da comunidade interessada, devendo ser, portanto, permanentemente construído ${ }^{33}$.

\section{Considerações finais}

O acesso à saúde é, incontestavelmente, uma prerrogativa fundamental do ser humano e, principalmente, do cidadão. Para o exercício de qualquer direito fundamental e para o cumprimento de qualquer dever, é preciso estar vivo e em condições mínimas de saúde. Por conseguinte, situar o direito à saúde como fundamental é consequência lógica e imprescindível do reconhecimento da condição humana no contexto jurídico.

\footnotetext{
${ }^{32}$ Segundo notícia veiculada no jornal local Diário Popular, em 3 de agosto de 2012, com a ocorrência das reuniões e tentativa de união de esforços com o poder público, foi possível verificar-se uma economia mensal de $\mathrm{R} \$ 150.000,00$ aos cofres públicos. PARCERIA resulta em economia de dinheiro público. Diário Popular, 03 ago. 2012. Disponível em: <http://www.diariopopular.com.br/index.php?n_sistema=3056\&id_noti-



${ }^{33}$ DALLARI, Sueli Gandolfi. O conteúdo do direito à saúde. In: COSTA, Alexandre Bernardino et al. (Orgs.). 0 direito achado na rua: introdução crítica ao direito à saúde. Brasília: CEAD; UnB, 2009. p. 99. Disponível em: <http://rededireitosanitario.fiocruz.br/wp-content/uploads/2011/08/O_Direito_Achado_na_Rua_PDFvol.4.pdf>. Acesso em: 03 set. 2013.
} 
Como o acesso à saúde é garantido pela Constituição 1988 e como um número relevante de brasileiros não tem fácil e amplo acesso, busca-se a efetividade do direito por intermédio do Poder Judiciário, que o assegura com sentenças que estabelecem uma obrigação de fazer sob a pena de bloqueio das contas públicas. Tal ingerência de um poder sobre outro - que outrora foi objeto de debate quanto a uma possível ofensa à separação de poderes, bem como quanto às discussões da ideal e adequada utilização do erário, pautadas pelo filtro da "reserva do possível"- atualmente se apresenta justificável, porquanto visa à tutela de um bem fundamental e necessário e que, portanto, deve estar acima de quaisquer controvérsias políticas, jurídicas ou burocráticas.

Todavia, é inegável que tal ingerência traz elevados impactos à gestão pública, fato que pôde ser comprovado com os dados colhidos no âmbito municipal. A realocação de recursos para a saúde ( $\mathrm{R} \$ 2.699 .939,44)$, que, por força de lei orçamentária, haviam sido inicialmente destinados a outras demandas, traz óbvio e latente prejuízo a essas "áreas" da despesa pública, haja vista tratar-se de uma cidade que vive uma realidade pouco abastada.

Contudo, os números apresentados pelo Poder Judiciário demonstram a demanda que o Estado-administração não consegue abarcar. Se o número de ações é alto, ele se deve à necessidade da sociedade em face ao acesso à saúde. Tais números traduzem a manifestação social no tangente à carência do serviço de saúde (em sentido amplo). Os gastos e o orçamento municipais mostram que o orçamento deve ser fortalecido no que se refere à rubrica da saúde, assim como a União e o Estado-membro devem, também, assumir com maior intensidade a corresponsabilidade pelo aporte financeiro à saúde quando o ente municipal desembolsa para além de seu orçamento a fim de atender as demandas sociais.

Nota-se a encruzilhada em que se encontra o gestor público municipal, que não tem um orçamento capaz de cobrir as despesas oriundas de demandas judiciais (que, por sua vez, refletem as demandas sociais) e os serviços públicos de saúde em sua totalidade (que deveriam ser devidamente oferecidos a fim de não ser necessária a discussão judicial da matéria, o que não ocorre). O déficit orçamentário municipal ocasionado pelas ações judiciais é reflexo do valor dos recursos destinados à saúde. Por isso, é preciso buscar maneiras de equacionar o problema entre a demanda de saúde e o valor da rubrica orçamentária da saúde.

Destarte, embora não de forma definitiva, como solução para a racional e adequada gestão dos recursos públicos, sem maiores prejuízos às outras demandas sociais e sem configurar-se um engessamento da administração pública em razão da atuação do Judiciário, pôde-se verificar que o caminho mais adequado é aquele que perpassa a atuação unificada do poder público, aliada à efetiva participação popular.

Somente sendo observados tais fatores, serão as necessidades racionalmente definidas e as metas para a solução dos problemas, lógica e gradualmente estabelecidas, podendo-se, daí, alcançar uma maior efetividade no direito à saúde junto à otimização dos recursos públicos em uma perspectiva republicana. 


\section{Referências}

BARROSO, Luís Roberto. Da falta de efetividade à judicialização excessiva: direito à saúde, fornecimento gratuito de medicamentos e parâmetros para a atuação judicial. Rio de Janeiro, 2007. Disponível em: <http://download.rj.gov.br/documentos/10112/168750/DLFE-29287. pdf/rev630402Dr.LuisRobertoBarroso.pdf>. Acesso em: 05 set. 2013.

CNS defende a regulamentação da EC no 29. Conselho Nacional de Saúde. Disponível em: <http://conselho.saude.gov.br/webec29/index.html>. Acesso em: 26 ago. 2013.

DALLARI, Sueli Gandolfi. O conteúdo do direito à saúde. In: COSTA, Alexandre Bernardino et al. (Orgs.). O direito achado na rua: introdução crítica ao direito à saúde. Brasília: CEAD; UnB, 2009. Disponível em: <http://rededireitosanitario.fiocruz.br/wp-content/uploads/2011/08/O_ Direito_Achado_na_Rua_PDF-vol.4.pdf>. Acesso em: 03 set. 2013.

FUNDEB pode financiar saúde. Carta Capital. Disponível em: <http://www.cartacapital.com. br/politica/fundeb-pode-financiar-saude >. Acesso em: 26 ago. 2013.

INSTITUTO BRASILEIRO DE GEOGRAFIA E ESTATÍSTICA. Disponível em: < http://www. ibge.gov.br>. Acesso em: 10 jun. 2013.

KÖLLING, Gabrielle; MASSAÚ, Guilherme Camargo. A concretização do direito à saúde na perspectiva republicana. Revista de Direito Sanitário, São Paulo, v. 12, n. 2, p. 11-36, 2011. Disponível em: <http://www.revistas.usp.br/rdisan/article/view/13247/15064>. Acesso em: 03 set. 2013.

LUNARDI, Valéria Lerch. Problematizando conceito de saúde, a partir do tema da governabilidade dos sujeitos. Revista Gaúcha de Enfermagem, Porto Alegre, v. 20, n. 1, p. 26-40, jan. 1999. Disponível em: <http://seer.ufrgs.br/RevistaGauchadeEnfermagem/article/ view/4219/2229>. Acesso em: 15 jun. 2013.

MARQUES, Silvia Bedim. Judicialização do direito à saúde. Revista de Direito Sanitário, São Paulo, v. 9, n. 2, p. 65-72, 2008. Disponível em: <http://www.revistas.usp.br/rdisan/article/ view/13117/14920>. Acesso em: 15 jun. 2013.

MENDES, Gilmar Ferreira; BRANCO, Paulo Gustavo Gonet. Curso de direito constitucional. São Paulo: Saraiva, 2011.

PARCERIA resulta em economia de dinheiro público. Diário Popular, 03 ago. 2012. Disponível em: <http://www.diariopopular.com.br/index.php?n_sistema=3056\&id_ noticia $=\mathrm{NjE} 0 \mathrm{NzQ}=\& i d \_$area $=\mathrm{Mg}==>$. Acesso em: 28 ago. 2013.

PREFEITURA DE PELOTAS. Portal do Servidor. Disponível em: < http://externo.pelotas. com.br:51000>. Acesso em: 15 ago. 2013.

RODRIGUES, Geisa de Assis. Direito sanitário. In: NUNES JÚNIOR, Vidal Serrano (Org.). Manual de direitos difusos. São Paulo, Verbatim, 2009. 
SARLET, Ingo Wolfgang. Os direitos fundamentais sociais na constituição de 1988. Revista Diálogo Jurídico, Salvador, ano 1, v. 1, n. 1, p. 1-45, abr. 2001. Disponível em: <http:// direitopublico.com.br/revistas/17082706/revista-dialogo-juridico-01-2001-ingo-sarlet.pdf > . Acesso em: 18 abr. 2013.

SOUZA, Celina. Políticas públicas: uma revisão da literatura. Revista Sociologias, Porto Alegre, ano 8, n. 16, p. 20-45, jul./dez. 2006. SciELO Brasil. Disponível em: <http://www.scielo.br/ pdf/soc/n16/a03n16>. Acesso em: 03 set. 2013.

\section{Agradecimentos}

Os autores agradecem à Secretaria de Saúde do Município de Pelotas, nas figuras da secretária Arita Bergmann, José Drummond de Macedo Neto e Nélson Martins Soares Sobrinho, Gerente da Assessoria Técnica - por ter disponibilizado prontamente os dados referentes ao total de gastos em saúde por ordem judicial.

Agradecem também à 6a Vara Cível da Comarca de Pelotas, na figura do magistrado titular, Luis Antônio Saud Teles, por ter fornecido os dados referentes às demandas judiciais relativas à temática da saúde.

Guilherme Camargo Massaú - Doutor em Direito pela Universidade do Vale do Rio dos Sinos; Mestre em Ciências Jurídico-Filosóficas pela Universidade de Coimbra; Especialista em Ciências Penais pela Pontifícia Universidade do Rio Grande do Sul. Professor da Faculdade de Direito e do Mestrado em Sociologia da Universidade Federal de Pelotas. Pelotas/RS, Brasil. E-mail: uassam@gmail.com.

André Kabke Bainy - Acadêmico da Faculdade de Direito da Universidade Federal de Pelotas. Estagiário do Ministério Público Federal, na Procuradoria da República no Município de Pelotas. Pelotas/RS, Brasil. E-mail: andrebainy@hotmail.com. 